\title{
Tsunami waveform inversion of the 2007 Bengkulu, southern Sumatra, earthquake
}

\author{
Yushiro Fujii ${ }^{1}$ and Kenji Satake ${ }^{2 *}$ \\ ${ }^{1}$ International Institute of Seismology and Earthquake Engineering (IISEE), Building Research Institute (BRI), \\ 1 Tachihara, Tsukuba, Ibaraki 305-0802, Japan \\ ${ }^{2}$ Geological Survey of Japan (GSJ), National Institute of Advanced Industrial Science and Technology (AIST), \\ Tsukuba Central 7, 1-1-1 Higashi, Tsukuba, Ibaraki 305-8567, Japan \\ (Received January 31, 2008; Revised July 7, 2008; Accepted July 23, 2008; Online published October 15, 2008)
}

\begin{abstract}
We performed tsunami waveform inversions for the Bengkulu, southern Sumatra, earthquake on September 12, $2007\left(M_{\mathrm{w}} 8.4\right.$ by USGS). The tsunami was recorded at many tide gauge stations around the Indian Ocean and by a DART system in the deep ocean. The observed tsunami records indicate that the amplitudes were less than several tens of centimeters at most stations, around $1 \mathrm{~m}$ at Padang, the nearest station to the source, and a few centimeters at the DART station. For the tsunami waveform inversions, we adopted 20-, 15- and 10-subfault models. The tsunami waveforms computed from the estimated slip distributions explain the observed waveforms at most stations, regardless of the subfault model. We found that large slips were consistently estimated at the deeper part $(>24 \mathrm{~km}$ ) of the fault plane, located more than $100 \mathrm{~km}$ from the trench axis. The largest slips of 6-9 m were located about 100-200 km northwest of the epicenter. The deep slips may have contributed to the relatively small tsunami for its earthquake size. The total seismic moment is calculated as $4.7 \times 10^{21} \mathrm{~N} \mathrm{~m}\left(M_{\mathrm{w}}=8.4\right)$ for the 10-subfault model, our preferred model from a comparison of tsunami waveforms at Cocos and the DART station.
\end{abstract}

Key words: 2007 southern Sumatra earthquake, tsunami source, tsunami waveform inversion, tide gauge, DART.

\section{Introduction}

An earthquake off the south coast of Bengkulu, southern Sumatra $\left(4.520^{\circ} \mathrm{S}, 101.374^{\circ} \mathrm{E}, M_{\mathrm{w}} 8.4\right.$ at $11: 10: 26 \mathrm{UTC}$ according to USGS) on September 12, 2007 generated a tsunami that resulted in 25 fatalities and 92 injured (41 severe and 51 minor) in Bengkulu and West Sumatera Provinces (International Federation of Red Cross and Red Crescent Societies, 2007). The source process of the 2007 Bengkulu earthquake has been inferred from teleseismic body waves (Ji, 2007a; Vallée, 2007a; Yagi, 2007; Yamanaka, 2007). Ji (2007a) and Yamanaka (2007) found a major asperity at a depth around $30 \mathrm{~km}$, while Yagi (2007) and Vallée (2007a) estimated a similar asperity and an additional one located in a deeper area. About a half day after the mainshock, the largest aftershock $\left(M_{\mathrm{w}} 7.9\right.$ according to USGS) occurred approximately $250 \mathrm{~km}$ north of the mainshock's epicenter; this also generated a tsunami. Because the tsunami from the largest aftershock overlapped with the later phases of the mainshock's tsunami, it is difficult to separate the tsunami signals on tide gauge records.

Tsunami surveys made immediately after the earthquake along approximately $300 \mathrm{~km}$ of the coast of southern Sumatra reported tsunami heights of up to about $4 \mathrm{~m}$ (Borrero et

*Present affiliation: Earthquake Research Institute (ERI), University of Tokyo, 1-1-1 Yayoi, Bunkyo-ku, Tokyo 113-0032, Japan.

Copyright (c) The Society of Geomagnetism and Earth, Planetary and Space Sciences (SGEPSS); The Seismological Society of Japan; The Volcanological Society of Japan; The Geodetic Society of Japan; The Japanese Society for Planetary Sciences; TERRAPUB al., 2007; Gunawan et al., 2007). Those tsunami heights are relatively small compared to the earthquake size of a magnitude of 8 . As expected by the teleseismic waveform inversions, the asperities deeper than $30 \mathrm{~km}$ may have contributed to the relatively smaller tsunami. We report here our calculation of tsunami waveform inversions to reveal the tsunami source of the 2007 Bengkulu earthquake. Lorito et al. (2008) also inverted tsunami waveforms recorded at eight tide gauges and a DART station to estimate the coseismic slip distribution.

\section{Tide Gauge and Bathymetry Data}

The tsunami generated by the 2007 Bengkulu, southern Sumatra, earthquake was recorded at more than 15 tide gauge stations around the Indian Ocean and by the DART system (Fig. 1) installed in the deep ocean, maintained by the Thai Meteorological Department (TMD) and operated by the National Oceanic and Atmospheric Administration (NOAA). Some of the tide gauge data have been collected by Global Sea Level Observing System (GLOSS) and were stored on the website of the University of Hawaii Sea Level Center (UHSLC). We downloaded digital data from the UHSLC's website as well as DART data from NOAA's website. We also used the tsunami waveforms recorded on four tide gauges operated by the Bureau of Meteorology (BoM), Australian Government. The locations of the tide gauges and the DART system are listed with those data sources in Table 1. These tide-gauge and DART records usually include ocean tides, which we remove using the following data processing. In order to retrieve a tsunami 
Table 1. List of tide gauge stations and DART system.

\begin{tabular}{lcccc}
\hline \multicolumn{1}{c}{ Station } & Lat. $(\operatorname{deg}: \min [: \mathrm{sec}])$ & Lon. $(\mathrm{deg}: \min [: \mathrm{sec}])$ & Data* $^{*}$ & Location** $^{*}$ \\
\hline Salalah & $16: 56.1 \mathrm{~N}$ & $54: 00.4 \mathrm{E}$ & $\mathrm{U}$ & $\mathrm{G} 2$ \\
Pt. La Rue & $4: 40 \mathrm{~S}$ & $55: 32 \mathrm{E}$ & $\mathrm{U}$ & $\mathrm{G} 1$ \\
Rodrigues & $19: 41 \mathrm{~S}$ & $63: 25 \mathrm{E}$ & $\mathrm{U}$ & $\mathrm{U}$ \\
Hanimaadhoo & $6: 46 \mathrm{~N}$ & $73: 10 \mathrm{E}$ & $\mathrm{U}$ & $\mathrm{G} 1$ \\
Male-B & $4: 11 \mathrm{~N}$ & $73: 32 \mathrm{E}$ & $\mathrm{U}$ & $\mathrm{G} 1$ \\
Gan & $0: 41 \mathrm{~S}$ & $73: 09 \mathrm{E}$ & $\mathrm{U}$ & $\mathrm{G} 1$ \\
Diego Garcia-C & $7: 17.4 \mathrm{~S}$ & $72: 23.6 \mathrm{E}$ & $\mathrm{U}$ & $\mathrm{G} 2$ \\
Colombo & $6: 59: 54 \mathrm{~N}$ & $79: 51: 12 \mathrm{E}$ & $\mathrm{B}$ & $\mathrm{B}$ \\
Sabang & $5: 50 \mathrm{~N}$ & $\mathrm{U}$ & $\mathrm{U}$ \\
Sibolga & $1: 45 \mathrm{~N}$ & $\mathrm{U}$ & $\mathrm{G} 1$ \\
Padang & $0: 57 \mathrm{~S}$ & $98: 46 \mathrm{E}$ & $\mathrm{U}$ & $\mathrm{G} 1$ \\
Cilacap & $7: 45 \mathrm{~S}$ & $100: 22 \mathrm{E}$ & $\mathrm{U}$ & $\mathrm{G} 1$ \\
Benoa & $8: 45 \mathrm{~S}$ & $109: 01 \mathrm{E}$ & $\mathrm{U}$ & $\mathrm{G} 1$ \\
Christmas & $10: 25: 45.8 \mathrm{~S}$ & $115: 13 \mathrm{E}$ & $\mathrm{B}$ & $\mathrm{B}$ \\
Cocos & $12: 07: 00.1 \mathrm{~S}$ & $105: 40: 09.6 \mathrm{E}$ & $\mathrm{B}$ & $\mathrm{B}$ \\
DART23401 & $8: 54: 18 \mathrm{~N}$ & $96: 53: 30.9 \mathrm{E}$ & $\mathrm{N}$ & $\mathrm{N}$
\end{tabular}

*: Agencies which provided the tsunami waveform data.

**: Sources for the locations of tide gauges and DART system.

U: University of Hawaii Sea Level Center (UHSLC; http://ilikai.soest.hawaii.edu/RSL/);

B: Bureau of Meteorology (BoM; ftp://ftp.bom.gov.au/anon/home/ntc/paul/tsunami/reports.html; last accessed 14 September 2007);

N: National Oceanic and Atmospheric Administration (NOAA; http://www.ndbc.noaa.gov/dart.shtml);

G1: Global Sea Level Observing System (GLOSS, United States National Sea Level Activities, 2007);

G2: GLOSS Station Handbook, British Oceanographic Data Centre (http://www.bodc.ac.uk/data/information_and_inventories/gloss_handbook/stations/).

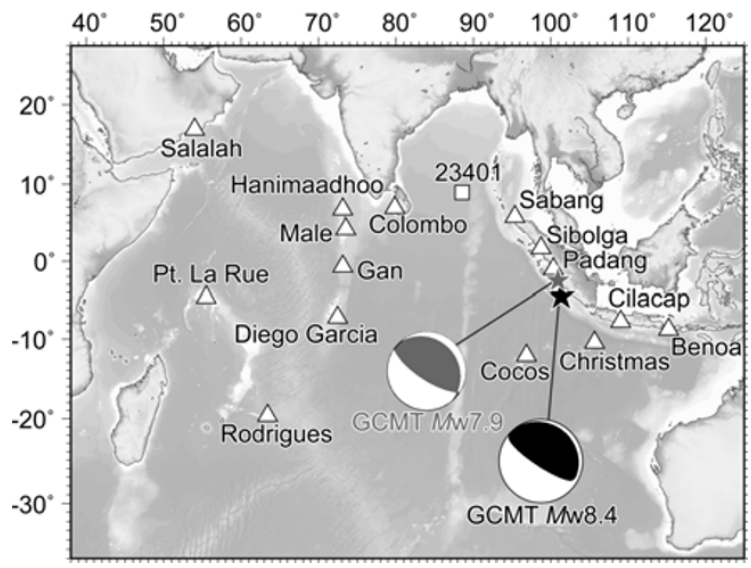

Fig. 1. Epicenters of the September 2007 Bengkulu earthquake (black star) and the largest aftershock (gray star). The triangles and square indicate the locations of available tide gauges and DART system, respectively. Global CMT solutions of the mainshock and the largest aftershock are also shown (lower hemisphere equal-area projection).

signal, we first approximate a tidal component by fitting a polynomial function; we then remove it from each original record. We then apply a moving average with the box car function ( $3 \mathrm{~min}$ wide) to the processed data to remove high-frequency noises, such as seismic waves on the ocean bottom sensor of the DART system. Amplitudes of the initial tsunami waves range from several centimeters to less than about $1 \mathrm{~m}$ (as shown later in Fig. 3). These tsunami waveforms will be used for tsunami waveform inversions.

Since phase velocities of shallow-water waves (tsunami) depend on water depth, accurate bathymetric data are essential for numerical tsunami computations. For the global ocean, a gridded bathymetry dataset digitized from contour maps is available from GEBCO (British Oceanographic Data Centre, 1997). We use this bathymetry data for calculating tsunami waveforms or Green's functions.

\section{Inversion Method}

\subsection{Subfault models}

In order to estimate the extent of the tsunami source and its slip distribution, we divide the tsunami source into 20 subfaults that cover not only the aftershock area during a half day after the mainshock (before the largest aftershock) but also the shallow region near the trench axis (Fig. 2). The size of each subfault is $50 \mathrm{~km} \times 50 \mathrm{~km}$ (Fig. 2, Table 2). The top depths are $3 \mathrm{~km}, 13.4 \mathrm{~km}, 23.8 \mathrm{~km}$, and $34.2 \mathrm{~km}$ for shallow subfaults (numbers 1-5), middle subfaults (6$10)$, deep subfaults (11-15), and deeper subfaults (16-20), respectively. We perform three sets of inversions to estimate the tsunami source using the 20-subfault model (all of the subfaults), the 15-subfault model (without the shallow subfaults), and the 10-subfault model (without the shallow and middle subfaults; only the deep and deeper subfaults). We assume an instantaneous rupture for all the subfault models because the tsunami propagation velocity is $0.1 \mathrm{~km} / \mathrm{s}$ at a water depth of $1,000 \mathrm{~m}$, which is much slower than the typical rupture velocity of a few kilometers per second. The epicenter is located on the southeastern part of the deep subfault (number 11). The focal mechanism of strike $327^{\circ}$, dip $12^{\circ}$, and slip angle $114^{\circ}$, obtained from the Global CMT solution of the mainshock, is assumed for all subfaults.

\subsection{Finite difference computation}

To calculate tsunami propagation from each subfault to stations, the linear shallow-water, or long-wave, equations are numerically solved using a finite-difference method (Satake, 1995). Details of the governing equations are described in Fujii and Satake (2007). The computation area 

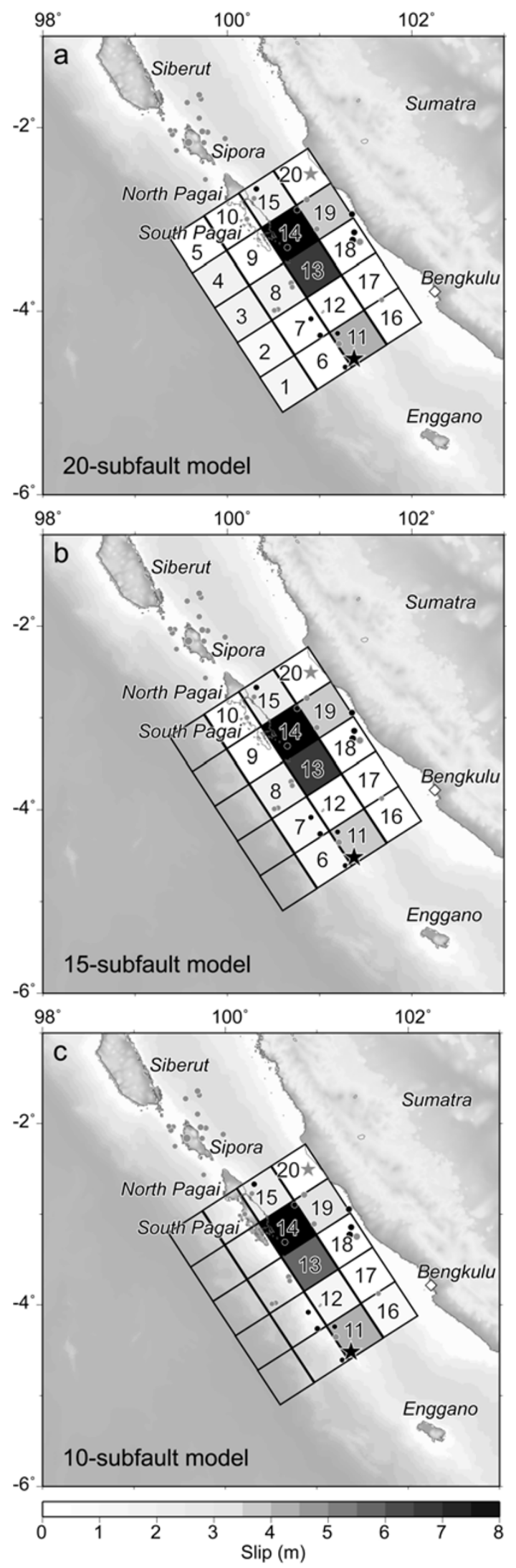

Fig. 2. Slip distributions estimated by tsunami waveform inversions adopting different subfault models (a: 20 subfaults, b: 15 subfaults, c: 10 subfaults) with subfault numbers. The black star shows the mainshock epicenter. Circles in black indicate aftershocks within a half day after the mainshock (before the largest aftershock). The largest aftershock and subsequent aftershocks within 1 day after that event are also shown in gray symbols.
Table 2. Slip distributions estimated by tsunami waveform inversions with different subfault models.

\begin{tabular}{rrrccc}
\hline No. & Lat. $\left({ }^{\circ} \mathrm{S}\right)$ & Lon. $\left({ }^{\circ} \mathrm{E}\right)$ & \multicolumn{3}{c}{ Slip and error $(\mathrm{m})$} \\
\cline { 4 - 6 } & & & 20 subfaults & 15 subfaults & 10 subfaults \\
\hline 1 & 5.100 & 100.600 & $1.24 \pm 0.64$ & - & - \\
2 & 4.721 & 100.355 & $0.53 \pm 0.27$ & - & - \\
3 & 4.341 & 100.110 & $1.86 \pm 0.71$ & - & - \\
4 & 3.962 & 99.865 & $1.73 \pm 1.01$ & - & - \\
5 & 3.583 & 99.620 & $0.00 \pm 0.00$ & - & - \\
6 & 4.854 & 100.977 & $0.14 \pm 0.17$ & $0.79 \pm 0.38$ & - \\
7 & 4.474 & 100.732 & $0.00 \pm 0.21$ & $0.64 \pm 0.52$ & - \\
8 & 4.095 & 100.487 & $1.60 \pm 0.69$ & $1.50 \pm 0.79$ & - \\
9 & 3.716 & 100.242 & $0.00 \pm 0.18$ & $0.00 \pm 0.15$ & - \\
10 & 3.337 & 99.997 & $0.40 \pm 0.64$ & $0.49 \pm 0.29$ & - \\
11 & 4.607 & 101.355 & $4.13 \pm 1.73$ & $3.99 \pm 1.87$ & $4.26 \pm 2.20$ \\
12 & 4.228 & 101.110 & $0.00 \pm 0.39$ & $0.00 \pm 0.26$ & $1.28 \pm 0.70$ \\
13 & 3.849 & 100.865 & $7.00 \pm 2.52$ & $6.68 \pm 2.60$ & $5.72 \pm 2.38$ \\
14 & 3.470 & 100.620 & $8.88 \pm 3.95$ & $9.03 \pm 4.01$ & $9.29 \pm 4.11$ \\
15 & 3.090 & 100.374 & $1.92 \pm 1.56$ & $2.08 \pm 1.54$ & $2.40 \pm 1.58$ \\
16 & 4.361 & 101.732 & $0.00 \pm 0.28$ & $0.00 \pm 0.62$ & $0.87 \pm 0.43$ \\
17 & 3.982 & 101.487 & $0.00 \pm 0.00$ & $0.00 \pm 0.00$ & $0.00 \pm 0.00$ \\
18 & 3.603 & 101.242 & $0.00 \pm 0.00$ & $0.00 \pm 0.26$ & $0.00 \pm 0.00$ \\
19 & 3.223 & 100.997 & $3.97 \pm 1.67$ & $3.60 \pm 1.71$ & $3.16 \pm 1.52$ \\
20 & 2.844 & 100.752 & $0.00 \pm 0.00$ & $0.00 \pm 0.03$ & $0.00 \pm 0.02$ \\
\hline & & & & &
\end{tabular}

Location (latitude [Lat.] and longitude [Lon.]) indicates the south corner of each subfault.

extends from $38^{\circ} \mathrm{E}$ to $125^{\circ} \mathrm{E}$ and $36^{\circ} \mathrm{S}$ to $27^{\circ} \mathrm{N}$ (Fig. 1). The bathymetric grid interval is basically $2^{\prime}$ (2 arc-min, about $3.7 \mathrm{~km}$ ); consequently, there are 2,610 × 1,890 grid points along the longitude and latitude directions, respectively. Near the coastal tide gauge stations, we use a finer grid interval of $24^{\prime \prime}$ ( 24 arc-s, about $0.75 \mathrm{~km}$ ) to better model nearshore propagation. Since the GEBCO dataset is gridded at $1^{\prime}$ intervals, we resample it at $2^{\prime}$ intervals for the basic grid and at $24^{\prime \prime}$ intervals for the finer grids around tide gauge stations, respectively. We set a minimum water depth on the coasts at $2 \mathrm{~m}$. Because the amplitudes of the 2007 tsunami were mostly up to a few tens of centimeters, the small amplitude assumption in linear shallow-water longwave equations is valid. A time step of $2 \mathrm{~s}$ is used to satisfy the stability condition for the finite-difference method.

As an initial condition for each subfault, static deformation of seafloor is calculated for a rectangular fault model (Okada, 1985). We also consider the effects of coseismic horizontal displacement in regions of steep bathymetric slopes (Tanioka and Satake, 1996). Tsunami waveforms at the tide-gauge and DART stations are calculated assuming a constant rise time (or slip duration) of $1 \mathrm{~min}$ on each subfault.

\subsection{Inversion}

We use non-negative least square method (Lawson and Hanson, 1974) and delete-half jackknife method (Tichelaar and Ruff, 1989) to estimate slips and errors, respectively. The observed tsunami waveforms are resampled at 1-min intervals; therefore, synthetic waveforms are also computed at 1-min intervals. We use the first cycles of the tsunami waveforms for the inversions because the limited resolution of bathymetry data may prevent accurate modeling of later phases, such as reflected waves. The total number of data 

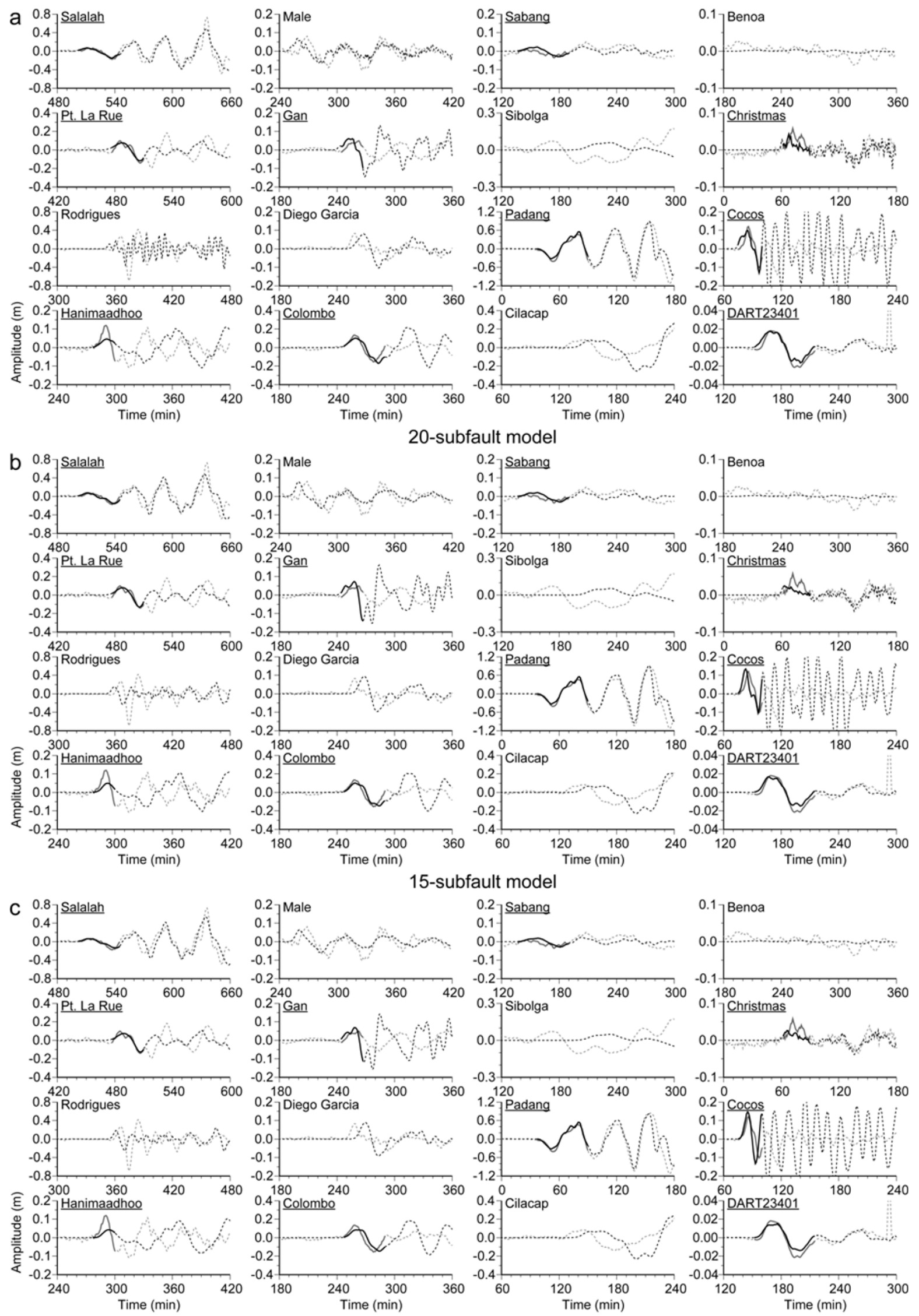

10-subfault model

Fig. 3. Comparisons of the observed (gray lines) and synthetic (black lines) tsunami waveforms computed from the slip distributions estimated by adopting the different subfault models (a: 20 subfaults, b: 15 subfaults, c: 10 subfaults). Time ranges shown by solid curves are used for the inversions; the dashed parts are not used for the inversions, but shown for comparison. Of the 16 waveforms shown here, we use parts of ten records (underlined stations) for the inversions. 
points used for the inversions is 407 . We weight the DART data tenfold higher than the other tide gauge data because the amplitude is much smaller, by one order of magnitude, than those of tide gauge records.

\section{Results and Discussion}

The inversion results are shown in Table 2 and Fig. 2. The result for the 10-subfault model (Fig. 2(c)), which is our preferred model (as described later), shows a tsunami source length of about $200 \mathrm{~km}$-if we neglect the small slip on the northwestern-most subfault (number 15) with large error. Around the epicenter, the estimated slip is up to $4 \mathrm{~m}$. The larger slips of $6-9 \mathrm{~m}$ are estimated on the northwestern part of the source area (subfaults 13 and 14). Most of the large slips are stably estimated on the deep and deeper subfaults $(>24 \mathrm{~km})$, regardless of the fault model, which supports the view that the generated tsunami was not large compared to the size of earthquake $(M \sim 8)$. The total seismic moments are calculated from these slip distributions as $5.1 \times 10^{21} \mathrm{~N} \mathrm{~m}\left(M_{\mathrm{w}}=8.4\right), 4.8 \times 10^{21} \mathrm{~N} \mathrm{~m}$ $\left(M_{\mathrm{w}}=8.4\right)$, and $4.7 \times 10^{21} \mathrm{~N} \mathrm{~m}\left(M_{\mathrm{w}}=8.4\right)$ for the 20-, 15-, and 10-subfault model, respectively. The rigidities assumed to calculate the moment increase to $3.0 \times 10^{10}$, $4.0 \times 10^{10}$, and $7.0 \times 10^{10} \mathrm{~N} / \mathrm{m}^{2}$ for the shallow, middle, and deep to deeper subfaults, respectively.

The synthetic waveforms generally agree with the observed ones at most stations (Fig. 3), regardless of subfault model. Differences in synthetic waveforms for different subfault models are much smaller than the differences between the observed and synthetic waveforms. However, at the Cocos and DART23401 stations, the synthetic waveforms from the 10-subfault model explain the observed waveforms better than those from the 20- and 15-subfault models. Since Cocos is located in the direction perpendicular to the trench axis, the tsunami waveform is more sensitive to the locations of slips in that direction compared to the other stations. For the 20- and 15-subfault models, the slips on the shallow or middle subfaults contribute to the faster synthetic tsunami arrivals and cause the longer durations of the first pulses than the observed ones (see Fig. 3). From this comparison, we prefer the 10-subfault model, although variance reductions from the 20 - and 15 -subfault models are slightly larger than that from the 10-subfault model. At some stations (e.g., Salalah, Padang or DART23401), the synthetic waveforms are well reproduced not only for the first cycles of tsunami waveforms (inversion time windows) but also for the later phases, which were not used in the inversions. Some stations' data are not used for the inversions because the first arrivals of the observed waveforms do not match with the synthetic ones (e.g., Rodrigues, Male or Diego Garcia) or the tsunami signal is too small relative to the background noise level (Benoa). However, even for these stations, the agreement between the synthetic and observed waveforms looks better for the 10-subfault model than for 20- or 15-subfault models.

The obtained slip distributions are quite similar to those of Yamanaka (2007) and Ji (2007a). Their results show an asperity with the largest moment at the northwestern part of the source region and at a depth of $\sim 30 \mathrm{~km}$. Our major asperity on the deep subfaults (numbers 13 and 14)
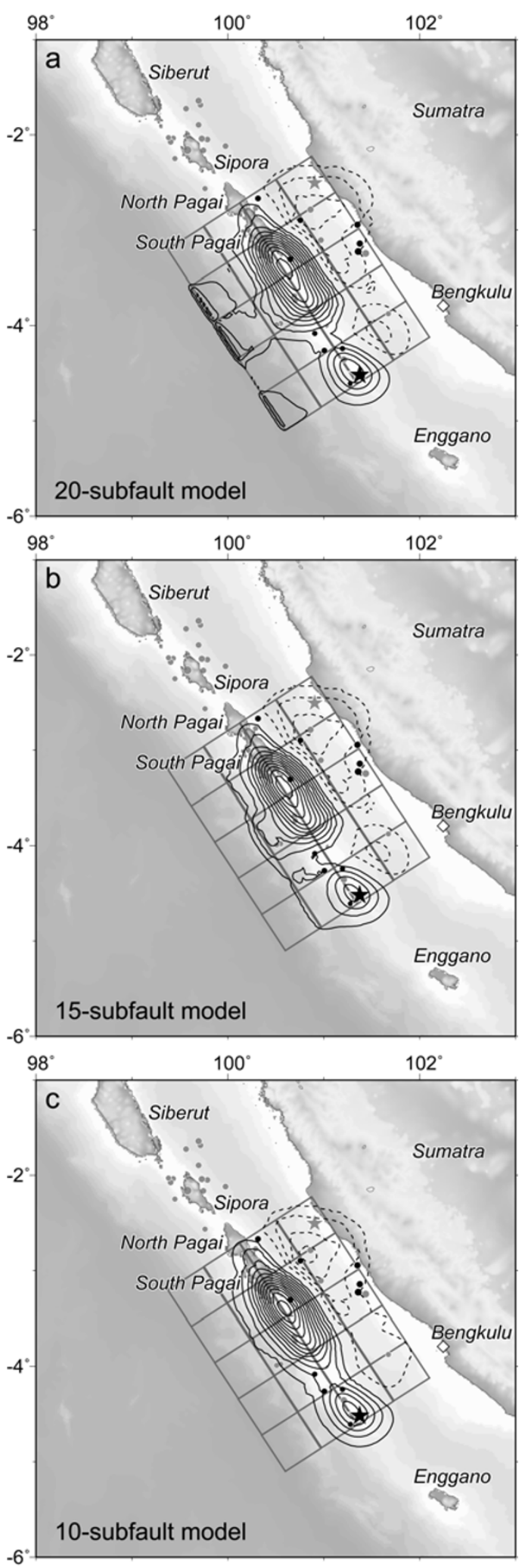

Fig. 4. Crustal deformations computed from the slip distributions estimated for the different subfault models (a: 20 subfaults, b: 15 subfaults, c: 10 subfaults). The solid contours indicate uplift, whereas the dashed lines indicate subsidence, with a contour interval of $0.2 \mathrm{~m}$.

may correspond to their asperities. Lorito et al. (2008) also estimated large slips $(\sim 10 \mathrm{~m})$ on 20 - to 30 -km-deep area, southeast of South Pagai, by inverting tsunami waveforms recorded at nine stations. Their result is quite similar to 
our slip distributions, although they made adjustments of travel times for some tide gauge datasets. Moreover, our slip distributions predict zero slip near the hypocenter of the largest aftershock (gray star in Fig. 2) for all of the subfault models. Ji (2007b) and Vallée (2007b) inverted the source process of the largest aftershock using teleseismic waveforms and found an asperity around the hypocenter. The zero slip on our subfault 20 corresponds to the single asperity of the largest aftershock.

Seafloor deformations calculated from the three subfault models (Fig. 4) show large uplifts up to $2.5 \mathrm{~m}$ southeast off South Pagai Island. There are a few minor discrepancies only in the shallow and middle areas among the three subfault models, as also shown in Fig. 2. A large earthquake occurred in this region in 1833, and the source models were constructed on the basis of uplifted corals (Natawidjaja et al., 2006). The seafloor deformation for our 10-subfault model is more similar to their deep source model $\left(M_{\mathrm{w}} 8.6\right)$ of the 1833 event than to their up-dip model reaching the trench axis $\left(M_{\mathrm{w}} 8.9\right)$. However, the deformation area of the 2007 earthquake is still shorter than the deformation area of the 1833 earthquake. The northwestern part of the 1833 source, the length of $\sim 100 \mathrm{~km}$, may exist as a seismic gap for another event. In addition, the shallow part of the up-dip model, which was not revealed as a tsunami source of the 2007 earthquake, may have a potential to generate threatening large tsunami accompanying a future event.

\section{Conclusions}

We have estimated the tsunami source of the 2007 Bengkulu, southern Sumatra, earthquake, using tsunami waveform data recorded in and around the Indian Ocean. Most of large slips are stably estimated on the deeper part $(>24 \mathrm{~km}$ ) regardless of the subfault model, which supports the view that a large tsunami was not generated relative to the size of the earthquake $(M \sim 8)$. The tsunami waveform inversion with the 10 -subfault model indicates that the tsunami source was $\sim 200 \mathrm{~km}$ long. The largest slips of 6-9 $\mathrm{m}$ are located on the northwestern part of the source area. The tsunami source model is quite similar to some of the source models predicting a deep asperity inferred from teleseismic waveform inversions. The obtained slip distribution yields a total seismic moment of $4.7 \times 10^{21} \mathrm{~N} \mathrm{~m}$ $\left(M_{\mathrm{w}}=8.4\right)$.

Acknowledgments. We thank the University of Hawaii Sea Level Center (UHSLC) and the Bureau of Meteorology (BoM) for providing us tide gauge data. The DART systems are operated by the National Oceanic and Atmospheric Administration (NOAA).
Most of the figures were generated by using Generic Mapping Tools (Wessel and Smith, 1998).

\section{References}

Borrero, J. C., R. Hidayat, and Suranto, Field Survey of the Tsunami Generated by the Mw 8.4 Earthquake of September 12, 2007, http:// www.usc.edu/dept/tsunamis/2005/tsunamis/2007_sumatra/field_survey_ web.pdf, 2007.

British Oceanographic Data Centre, The Centenary Edition of the GEBCO Digital Atlas (CD-ROM), 1997.

Fujii, Y. and K. Satake, Tsunami Source of the 2004 Sumatra-Andaman Earthquake inferred from Tide Gauge and Satellite Data, Bull. Seismol. Soc. Am., 97, S192-S207, 2007.

Gunawan, I., A. Suhandi, and B. Suryo, Tsunami field observation in Bengkulu Earthquake at 11:10 UTC and 101.22E; 4.59S Depth $10 \mathrm{~km}$, Mw (mB) 7.9, (ITIC Tsunami Bulletin Board), 2007.

International Federation of Red Cross and Red Crescent Societies, Indonesia: Bengkulu Earthquake, Information Bulletin no. 5, 1-3, 2007.

Ji, C., Preliminary Result of the Sep 12, 2007 Sumatra Earthquake, http:// earthquake.usgs.gov/eqcenter/eqinthenews/2007/us2007hear/finite_fault. php, 2007a.

Ji, C., Preliminary Result of the Sep 12, 2007 Mw 7.9 Kepulauan Earthquake, http://earthquake.usgs.gov/eqcenter/eqinthenews/2007/ us2007hec6/finite_fault.php, 2007b.

Lawson, C. L. and R. J. Hanson, Solving least squares problems, 340 pp., Prentice-Hall, Inc., Englewood Cliffs, N.J., 1974.

Lorito, S., F. Romano, A. Piatanesi, and E. Boschi, Source process of the September 12, 2007, Mw 8.4 southern Sumatra earthquake from tsunami tide gauge record inversion, Geophys. Res. Lett., 35, L02310, doi:02310.01029/02007GL032661, 2008.

Natawidjaja, D. H., K. Sieh, M. Chlieh, J. Galetzka, B. W. Suwargadi, H. Cheng, R. L. Edwards, J. P. Avouac, and S. N. Ward, Source parameters of the great Sumatran megathrust earthquakes of 1797 and 1833 inferred from coral microatolls, J. Geophys. Res., 111, B06403, doi:06410.01029/02005JB004025, 2006

Okada, Y., Surface Deformation Due to Shear and Tensile Faults in a HalfSpace, Bull. Seismol. Soc. Am., 75, 1135-1154, 1985.

Satake, K., Linear and Nonlinear Computations of the 1992 Nicaragua Earthquake Tsunami, Pure Appl. Geophys., 144, 455-470, 1995.

Tanioka, Y. and K. Satake, Tsunami generation by horizontal displacement of ocean bottom, Geophys. Res. Lett., 23, 861-864, 1996.

Tichelaar, B. W. and L. J. Ruff, How good are our best models? Jackknifing, Bootstrapping, and earthquake depth, Eos Trans. AGU, 70, 593, 605-606, 1989.

United States National Sea Level Activities, U.S. National Report 2007, Global Sea Level Observing System, 69 pp., UNESCO, Paris, 2007.

Vallée, M., Mw=8.5 07/09/12 Sumatra earthquake, http://geoazur. unice.fr/SEISME/SUMATRA120907/note1.html, 2007a.

Vallée, M., Mw=7.7 07/09/12 Sumatra-Kepulauan earthquake, http:// geoazur.unice.fr/SEISME/SUMATRA120907_2/note1.html, 2007b.

Wessel, P. and W. H. F. Smith, New, improved version of the Generic Mapping Tools released, Eos Trans. AGU, 79, 579, 1998.

Yagi, Y., http://www.geo.tsukuba.ac.jp/press_HP/yagi/EQ/20070912/, 2007.

Yamanaka, Y., http://www.seis.nagoya-u.ac.jp/sanchu/Seismo_Note/2007/ NGY4.html, 2007.

Y. Fujii (e-mail: fujii@kenken.go.jp) and K. Satake 